\title{
On the Wall Jet From the Ring Crevice of an Internal Combustion Engine
}

\author{
L.D. Cloutman \\ R.M. Green
}



AUG 16 iBSG

OSTI

\section{May 1996}

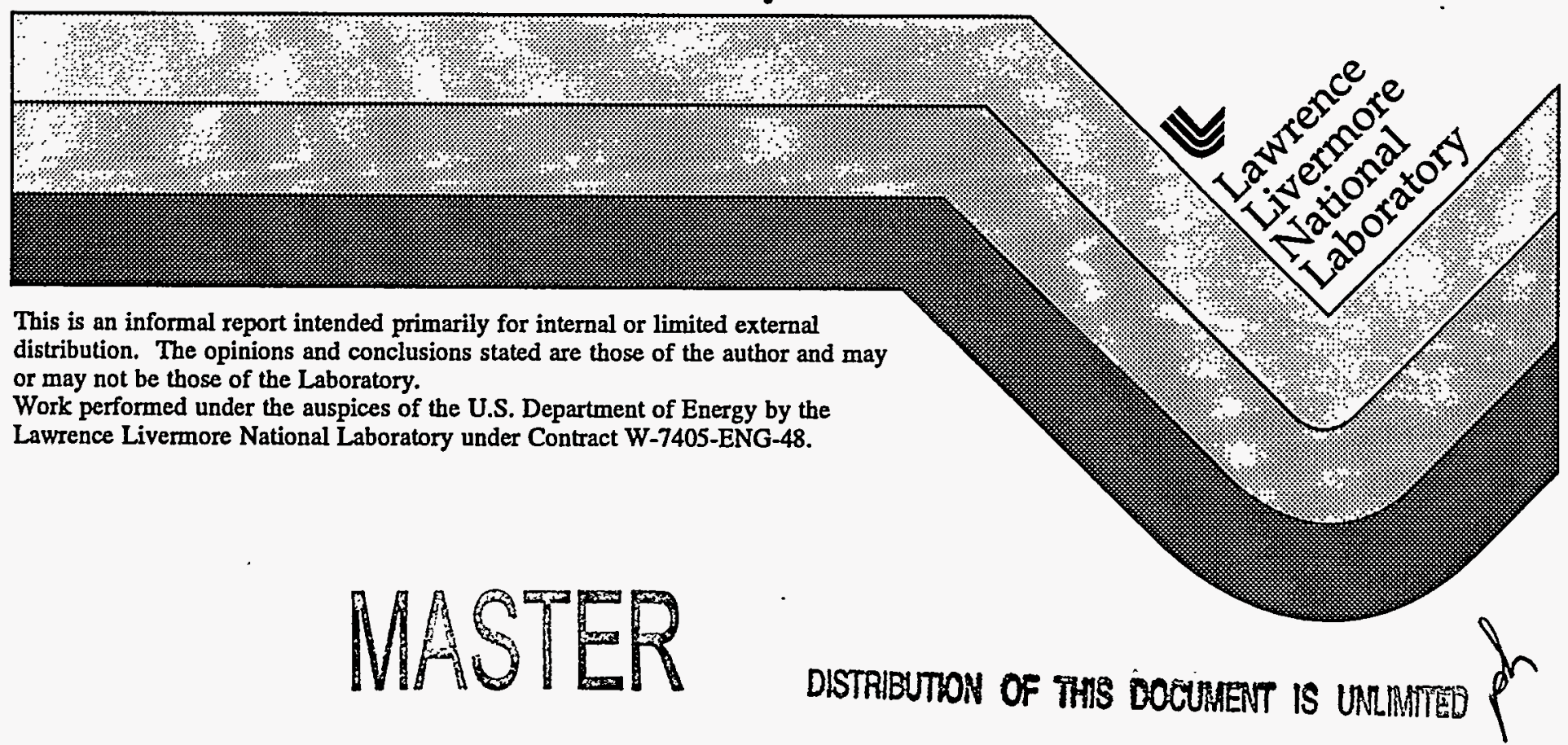




\section{DISCLAIMER}

This document was prepared as an account of work sponsored by an agency of the United States Government. Neither the United States Government nor the University of California nor any of their employees, makes any warranty, express or implied, or assumes any legal liability or responsibility for the accuracy, completeness, or usefulness of any information, apparatus, product, or process disclosed, or represents that its use would not infringe privately owned rights. Reference herein to any specific commercial product, process, or service by trade name, trademark, manufacturer, or otherwise, does not necessarily constitute or imply its endorsement, recommendation, or favoring by the United States Government or the University of California. The views and opinions of authors expressed herein do not necessarily state or reflect those of the United States Government or the University of California, and shall not be used for advertising or product endorsement purposes.

This report has been reproduced directly from the best available copy.

Available to DOE and DOE contractors from the Office of Scientific and Technical Information

P.O. Box 62, Oak Ridge, TN 37831

Prices available from (615) 576-8401, FTS 626-8401

Available to the public from the

National Technical Information Service

U.S. Department of Commerce

5285 Port Royal Rd.

Springfield, VA 22161 


\section{DISCLAIMER}

Portions of this document may be illegible in electronic image products. Images are produced from the best available original document. 


\title{
ON THE WALL JET FROM THE RING CREVICE OF AN INTERNAL COMBUSTION ENGINE
}

\author{
Lawrence D. Cloutman \\ Lawrence Livermore National Laboratory \\ and
}

Robert M. Green

Sandia National Laboratories, California

Numerical simulations and experiments of the jetting of gases from the ring crevices of a. laboratory engine shortly after exhaust valve opening showed an unanticipated radial flow of the crevice gases into the main combustion chamber. We report well-resolved numerical simulations of a wall jet that show that this radial motion is driven by vorticity generation in the wall boundary layer and at the corner of the piston crown. 


\section{INTRODUCTION}

In recent PLIF imaging experiments on flows from the ring crevice of an internal combustion engine, Bob Green found what appears to be a wall jet emerging from the crevice during the blowdown following exhaust valve opening near bottom dead center [1]. However, the jet does not stay attached to the cylinder wall, but the vortex ring at the jet tip detaches from the wall and moves inward radially. Shaheen Tonse has performed some preliminary simulations of this jet using the KIVA-3 fluid dynamics program and finds the same qualitative behavior [2]. This result raised the question of the mechanism that causes the jet to separate from the wall. The purpose of this report is to describe the mechanism for this separation.

The wall jet is one of the classic flow systems in fluid mechanics, and this separation is in fact well known in other contexts. Figure 162. of Van Dyke [3] show a well-developed, late-time version of a wall jet, namely a boundary layer on a flat plate, that shows bursting with vortex pairs similar to what was observed in the engine. Other relevant figures are found in the same section and around Fig. 110. A similar example is discussed by Bajura and Catalano [4]. Another example . is the boundary layer on the wall of a shock tube used to study a Richtmyer-Meshkov instability [5]. We note that the interface between the two fluids in that problem is analogous to the contact surface between the inflowing and ambient media in the ring crevice problem. To clearly illustrate this separation phenomenon, we performed two numerical simulations of a wall jet under conditions similar to those found near the ring crevice of an internal combustion engine during blowdown after . exhaust valve opening. One case uses a free-slip boundary condition on the cylinder wall, and the other uses a no-slip condition. These calculations are sufficient to demonstrate the fundamental physical processes at work.

Our approach to demonstrating the mechanism of the wall jet separation is to simplify the problem so there are no irrelevant factors clouding the analysis. These factors include piston motion, chemistry, wall heat transfer, and residual turbulence or other gas motions in the bulk gas. Our calculations show that the separation is a purely fluid dynamical phenomenon associated 
with the boundary layer on the cylinder wall and vorticity generation on the corner of the piston. Naturally, these other phenomena may modify the details of the wall jet, but the basic phenomenon is a robust feature of boundary layer flows.

Section II describes the experiment. Section III presents the governing equations and describes the gas physics. Section IV describes the geometry of the experimental apparatus and the problem setup. Section V describes two numerical solutions, one using a free-slip wall and the other using a no-slip wall. Conclusions are presented in Section VI.

\section{THE EXPERIMENT}

Using a single-cylinder research engine allowing optical access to the cylinder, we produced planar laser-induced fluorescence (PLIF) images of acetone dopant in the unburned fuel exiting the upper ring land crevice. The experimental arrangement is shown in Fig. 1. We obtained a sequence of images late in the power stroke and early in the exhaust stroke which revealed the existence of a jet-like structure exiting the crevice. Two typical images are shown in Fig. 2. The part of the combustion chamber shown in the figure is approximately $2 \mathrm{~cm}$ wide. The end-gap of the rings was pinned at a location diametrically opposed to the region being imaged, so the phenomena observed could not be attributed to flow through this gap. What we expected to see was a thin layer of unburned mixture laid down along the cylinder wall during the power stroke, which was then scraped up by the piston during the exhaust stroke and entrained in the corner roll-up vortex. But what we see instead is a jet emerging from the crevice just after bottom dead center. At late times, the tip of the jet develops an asymetric vortex pair that recedes from the wall. This behavior is typical of wall jets, as we discuss in the following sections. The tip velocity is approximately $600 \mathrm{~cm} / \mathrm{s}$ as determined from a crude measurement of the tip positions in the two -panels. 


\section{GOVERNING EQUATIONS}

The simulations were performed with the COYOTE computational fluid dynamics program [6], which is based on the full transient Navier-Stokes equations. The model includes a real-gas thermal equation of state, arbitrary chemical kinetics, transport coefficients from a Lennard-Jones model, a simple radiative heat loss model, and mass diffusion based on the full Stefan-Maxwell equations. Chemistry and radiation are omitted from the present calculations.

Mass conservation is expressed by the continuity equation for each species $\alpha$ :

$$
\frac{\partial \rho_{\alpha}}{\partial t}+\nabla \cdot\left(\rho_{\alpha} \vec{u}\right)=-\nabla \cdot \vec{J}_{\alpha}+R_{\alpha}
$$

where $\rho_{\alpha}$ is the density of species $\alpha, \vec{u}$ is the fluid velocity, $\vec{J}_{\alpha}$ is the diffusional mass flux of species $\alpha$, and $R_{\alpha}$ is the rate of change of species $\alpha$ by chemical reactions. The diffusional flux is a complex function of the flow. that is approximated by the formalism of Ramshaw $[7,8]$, which.is an approximate treatment of the full Stefan-Maxwell equations.

The momentum equation is

$$
\frac{\partial(\rho \vec{u})}{\partial t}+\nabla \cdot(\rho \vec{u} \vec{u})=\sum_{\alpha} \rho_{\alpha} \vec{F}_{\alpha}-\nabla P-\nabla \cdot \mathcal{S}
$$

where $P$ is the pressure, and $\vec{F}_{\alpha}$ is the body force per unit mass acting on species $\alpha$, which in most applications is the gravitational acceleration $\vec{g}$. The viscous stress tensor is

$$
\mathcal{S}=-\mu\left[\nabla \vec{u}+(\nabla \vec{u})^{T}\right]-\mu_{1}(\nabla \cdot \vec{u}) \mathcal{U}
$$

where $\mu$ is the coefficient of viscosity, $\mu_{1}$ is the second coefficient of viscosity, and $\mathcal{U}$ is the unit tensor.

We choose the thermal internal energy equation to express energy conservation:

$$
\frac{\partial(\rho I)}{\partial t}+\nabla \cdot(\rho I \vec{u})=-P \nabla \cdot \vec{u}-\mathcal{S}: \nabla \vec{u}-\nabla \cdot \vec{q}+\sum_{\alpha} H_{\alpha} R_{\alpha}+\sum_{\alpha} \vec{F}_{\alpha} \cdot \vec{J}_{\alpha}-\mathcal{L}_{\mathrm{rad}}
$$

where $I$ is the specific thermal internal energy, and $H_{\alpha}$ is the heat of formation of species $\alpha$. Note that for $\vec{F}_{\alpha}=\vec{g}$, the next-to-the-last term vanishes. The heat flux $\vec{q}$ is approximated by the sum 
of Fourier's law and enthalpy diffusion:

$$
\vec{q}=-\kappa \nabla T+\sum_{\alpha} h_{\alpha} \vec{J}_{\alpha}
$$

where $h_{\alpha}$ is the specific enthalpy of species $\alpha$. The radiative heat loss term $\mathcal{L}_{\text {rad }}$ is described in [9]. We assume $R_{\alpha}=\mathcal{L}_{\mathrm{rad}}=0$ in the present work.

The equation of state is assumed to be given as the sum of the partial pressures of an ideal gas for each species. Transport coefficients are computed from the Lennard-Jones model [10]. The JANAF tables [11-13] provide a homogeneous set of thermochemical data for a large collection of materials, and these tables are used to supply the specific enthalpy and heat of formation for each species of interest.

\section{PROBLEM DESCRIPTION}

The geometry of the calculation is shown in Fig. 3. Table 1 lists the COYOTE input file. The grid is $1.0 \mathrm{~cm}$ by $2.0 \mathrm{~cm}$ with a uniform 100 by .200 grid in Cartesian coordinates. The orifice at the bottom of the mesh has a radius of $0.16 \mathrm{~cm}$; and the top of the mesh is open with a fixed pressure of $1.013 \times 10^{5} \mathrm{~Pa}$. Species densities may be found in the input file. The initial ambient . medium is air at $750 \mathrm{~K}$, and the inflowing gas is an ethylene-air mixture at $300 \mathrm{~K}$ and equivalence ratio of 0.8 . The inflow velocity is $2.0 \times 10^{4} \mathrm{~cm} / \mathrm{s}$. The kinematic viscosity of the inflowing gas is $0.15 \mathrm{~cm}^{2} / \mathrm{s}$, which gives a jet Reynolds number of $2.1 \times 10^{4}$. The kinematic viscosity for the ambient medium is $\mathbf{0 . 7 5}$. The right boundary is a rigid free-slip wall. Two calculations were done with different boundary conditions on the left: one uses a free-slip boundary, and the other uses a no-slip boundary.

Our inflow boundary condition is the type (ii) with specified density of Rudy and Strikwerda [14]. In addition, we impose a restriction against inflow along any outflow boundary for reasons discussed in an earlier report [15], although this restriction was not needed in these calculations.

Both problems were run for 2000 cycles, which is enough time for the wall jet to move nearly the length of the mesh. We found that in spite of the fine zoning, it was necessary to use the 
subgrid-scale turbulence model to prevent the appearance of too much energy at the grid scale. This observation is consistent with the jet Reynolds number of $2.1 \times 10^{4}$, which would require at least another order magnitude improvement in resolution before reaching the smallest scales of turbulence. That is, a direct numerical simulation (DNS) would require well over $10^{3}$ zones in each of three dimensions. The present runs were made using the standard COYOTE subgrid-scale (SGS) turbulence transport model [16], and the inflowing SGS turbulence kinetic energy density is $2 \%$ of the incoming mean-flow kinetic energy density.

\section{NUMERICAL SOLUTIONS}

Figure 3 shows a comparison of the isotherms for the free-slip and no-slip cases.at comparable times, a little over $0.04 \mathrm{~ms}$ after start-up. The contour values are equally spaced with.a spacing of $10 \%$ of the difference between the maximum and minimum function values. The value of the B contour is the minimum plus the contour spacing, and so on. The jet opening is located at the lower left corner of the mesh. The top boundary has a fixed pressure of 1 atm; and the left and right boundaries are rigid walls. In the left panel, the left wall imposes.an adiabatic free-slip condition, and in the right panel, the left wall imposes an adiabatic no-slip condition. The tip of. the jet collapses into a vortex that moves parallel to the wall in the free-slip case. This type of flow is similar to the axisymmetric vortex ring seen, for example, at the tip of the free jet in Fig. 76 of Van Dyke [3]. The flow past the corner of the piston is an intense source of vorticity, and a periodic sequence of such vortices will be shed as long as the jet is operating. This type of flow is shown in several of the figures in Van Dyke. The right panel shows the effect of a no-slip boundary condition. We still have vorticity generated by the piston corner, and in addition we now have vorticity of the opposite sign generated by the boundary layer along the left wall. Furthermore, boundary layer drag has caused the point at which the jet contacts the wall to.lag behind other parts of the jet tip. Initially, the contact point of the jet on the wall will move upward at approximately the same rate as the vortex center since the no-slip velocity condition at the point of contact makes the vortex 
move much like a pinion gear rolling along a rack. As we shall see, these vortices will grow as the jet ages, making the "axis" of the jet stay tilted over and the jet tip will continue to move to the right as well as upward.

Figure 4 shows the mass fraction of ethylene for the same cases as in Fig. 3. At time zero, the contours show an interface at the jet orifice. This planar set of contours with zero spacing represents. a contact surface between the ambient and jet materials. Numerical diffusion quickly spreads the contours over a distance of 2-4 zones (the obstacle representing the piston crown is 6 zones thick), but the resolution is still sufficient to show the stretching and roll-up of the contact surface by the vortex. Diffusion, both turbulent and molecular, act to dissipate slowly the highly stretched parts of the contact surface. It is clear from the right-hand panel that the vortex generated by the wall boundary layer is weaker than the one generated by the piston corner.

Figure 5 shows the velocity vectors for the same cases as Fig. 3 . The free-slip case shows only the single vortex shed by the piston, but the no-slip. case shows also the smaller, weaker vortex climbing the wall in what appears to be the rack-and-pinion mode. The velocity vector plot in Fig. 6 zooms in on this region and plots a vector for every zone. It shows that this vortex actually induces a reverse flow down the left wall. This flow is in a layer slightly less than $0.5 \mathrm{~mm}$ thick, and the flow speed is an order of magnitude slower than the upflow in the main body of the jet. It is the presence of this second vortex that forces the main body of the jet flow off the wall. Once the flow becomes diverted, the weak reverse flow near the wall keeps the jet off the wall, although the contact point.will continue to rise.

Figure 7 shows the vorticity for the same cases as Fig. 3. We see the strong vorticity generation at the lip of the piston in both cases, with vorticity being advected far downstream. In the noslip case, there is strong vorticity generation in the boundary layer along the left wall. This plot illustrates the difficulty sometimes encountered in interpreting vorticity plots of turbulent flows. The tip vortices that are so prominent in the other functions are not at all distinct in the vorticity plot. They only are hinted at by a single contour for the piston-induced vortex and not at all for the boundary-layer-induced vortex. As the vorticity is advected downstream, it gets smaller in 
magnitude and the presence of small but resolved eddies (a feature of the SGS turbulence model) causes a lot of clutter. We shall revisit this issue in the next set of plots.

Figures 8-12 show the jet just after a time of $0.1 \mathrm{~ms}$. Both wall jets have undergone considerable development. The free-slip case is still attached to the wall, and the piston has shed a secondary vortex. In the no-slip case; a secondary vortex has been shed on both sides of the jet. The no-slip jet continues moving upward and to the right, and the point of attachment keeps rising slowly in spite of the thin, weak reverse flows along a significant part of the left wall. The reverse flows are growing stronger, and they cause the point of attachment to lag further and further behind the tip vortex. Zoomed velocity vector plots similar to Fig. 6 show that the reverse flows are correlated with the vortices along the right side of the jet. . The wall-induced vortex in the jet tip has nearly decayed away, while the piston-induced vortex is quite strong. We suspect that the stronger vortex has stretched and diffused the weaker vortex as it attempts to entrain it: Once again, the standard vorticity plots shown in Fig. 11 show. the intense vorticity generation and vorticity advection, but no clear indication of the jet tip vorticity beyond a subtle hint.in only the . free-slip case.

Figure 12 shows the vorticity plots for the free-slip case with the contour values adjusted to bring out the features in the jet-tip vortex. The left panel shows the plot.with contours evenly spaced about zero. The F contour indicates zero vorticity. The plot is quite complex, in sharp contrast to the relatively clean vorticity contours of the laminar solutions of Conlon and Lichter [17]. The right contour shows the contour plots for only the positive vorticity, with the A contour indicating zero vorticity. The outer rim of the tip vortex has negative vorticity. There is a set of four vortex centers, two of each sign, in the interior of the tip vortex. There is a region of positive vorticity just inside the tip of the jet and another one to the right of the tip vortex. In addition, there is a pair of positive vortex regions just above the orifice and on either side of the tall region . of negative vorticity shed by the piston corner:

Figure 13 shows the vorticity for the no-slip solution with modified contour values. As in the case of the left panel of Fig. 12, the F contour indicates zero vorticity. We see the tall region of 
negative vorticity shed by the pison, and the layer of positive vorticity all along the left wall.

Figures 14 and 15 show the jet just before a time of $0.14 \mathrm{~ms}$. The no-slip jet is interacting strongly with the right wall, so the calculations are terminated at this point. However, we see the shedding of two secondary vortices from the piston corner, the first of which is about to be engulfed in the tip vortex in the free-slip case. In the no-slip case, there appear to be two secondary vortices shed 'by the boundary layer as well. As expected, at no time does the free-slip jet try to separate from the wall. This is in contrast to the results of Conlon and Lichter [17], whose inflowing fluid contained a significant amount of vorticity in most cases, including the free-slip cases.

The work of Tonse [2] suggests that the flow speed out of the crevice is one or two orders of magnitude smaller than that used here. Consequently, two additional pairs of solutions were begun with Reynolds numbers of 21 and 210. The former solution will test the hypothesis of Conlon and Lichter [17] that no separation will occur for Reynolds numbers below about 50. The latter solution will correspond to Tonse's lowest flow speeds, so we will have bracketed the Reynolds number range that can be expected in the engine. Since both cases are laminar, no turbulence model is used. Both cases are behaving qualitatively the same as the high Reynolds number case reported here. A plot of fuel mass fraction in the Reynolds number 210 case is shown in Fig. 16. We see the jet is behaving qualitatively similar to the high Reynolds number case, but on a longer time scale. Up to this point no secondary vortices have been shed. A more detailed follow-up report will be prepared upon completion of the calculations.

\section{CONCLUSIONS}

The COYOTE hydrodynamics program has been used to simulate the flow of gases out of the ring crevice of an internal combustion engine. We simplified the problem by neglecting piston motion, chemistry, wall heat transfer, and residual gas motions to isolate the mechanism that separates the crevice jet from the cylinder wall when the wall jet in is contact with a no-slip wall. No separation occurs with a free-slip wall. The separation in the no-slip case occurs as a 
consequence of the generation of vorticity by both the boundary layer on the cylinder wall and . the corner of the piston. A pair of unequal counterrotating vortices is created at the tip of the jet. The vortex next to the wall produces a reverse flow near the wall, forcing the main jet flow to be deflected away from the wall and between the two vortices. At late times, secondary vortices are periodically shed in all cases. While the details of the development of any indvidual jet will be influenced by the neglected factors that will exist in the physical engine, the separation phenomenon is a fundamental, robust result of simple fluid dynamical factors associated with the boundary layers in the engine.

\section{ACKNOWLEDGMENTS}

I thank Alfred Buckingham, and Shaheen Tonse for many helpful discussions.

\section{REFERENCES}

1. Green, R. M., private communication, 1996.

2. Tonse, S., "Numerical Simulations of Emerging Piston Crevice Gases," submitted to SAE Fuels and Lubes Conference, 1996.

3: Van Dyke, M., "An Album of Fluid Motion," The Parabolic Press, Stanford, CA, 1982.

4. Bajura, R. A. and Catalano, M. R., J. Fluid Mech., 70:773 (1975).

5. Cloutman, L. D. and Wehner, M. F., Phys. Fluids A 4:1821 (1992).

6. Cloutman, L. D., "COYOTE: A Computer Program for 2-D Reactive Flow Simulations," Lawrence Livermore National Laboratory report UCRL-ID-103611, 1990.

7. Ramshaw, J. D., J. Non-Equilib. Thermodyn. 15:295 (1990).

8. Ramshaw, J. D., J. Non-Equilib. Thermodyn. 18:121 (1993).

9. Cloutman, L. D., "Numerical Simulation of Radiative Heat Loss in an Experimental Burner;" Lawrence Livermore National Laboratory report UCRL-JC-115048, presented at the 1993 Fall Meeting of the Western States Section Meeting of the Combustion Institute, 1993. -

10. Cloutman, L. D., "A Database of Selected Transport Coefficients for Combustion Studies," Lawrence Livermore National Laboratory report UCRL-ID-115050, 1993. 
11. Stull, D. R. and Prophet, H., JANAF Thermochemical Tables, 2nd ed. (U. S. Department of Commerce/National Bureau of Standards, NSRDS-NBS 37, June 1971).

12. Chase, M. W., Curnutt, J. L., Hu, A. T., Prophet, H., Syverud, A. N., and Walker, L. C., JANAF Thermochemical Table, 1974 Supplement, J. Phys. Chem. Ref. Data 3:311 (1974).

13. Chase, M. W. Jr., Davies, C. A., Downey, J. R. Jr., Frurip, D. J., McDonald, M. A., and Syverud, A. N., JANAF Thermochemical Tables, Third Edition, Parts I and II. Supplement No. 1, J. Phys. Chem. Ref. Data 14 (1985).

14. Rudy, D. H. and Strikwerda, J. C., Computers \& Fluids 9:327 (1981).

15. Cloutman, L. D., "Numerical Simulation of Turbulent Mixing and Combustion Near the Inlet of a Burner," Lawrence Livermore National Laboratory report UCRL-JC-112943, 1993.

16. Cloutman, L. D., Computers \& Fluids 17:437 (1989).

17. Conlon, B. P. and Lichter, S., Phys. Fluids 7:999 (1995). 
Table 1.

COYOTE Input File

Base Case Input - Noslip Wall, cgs units

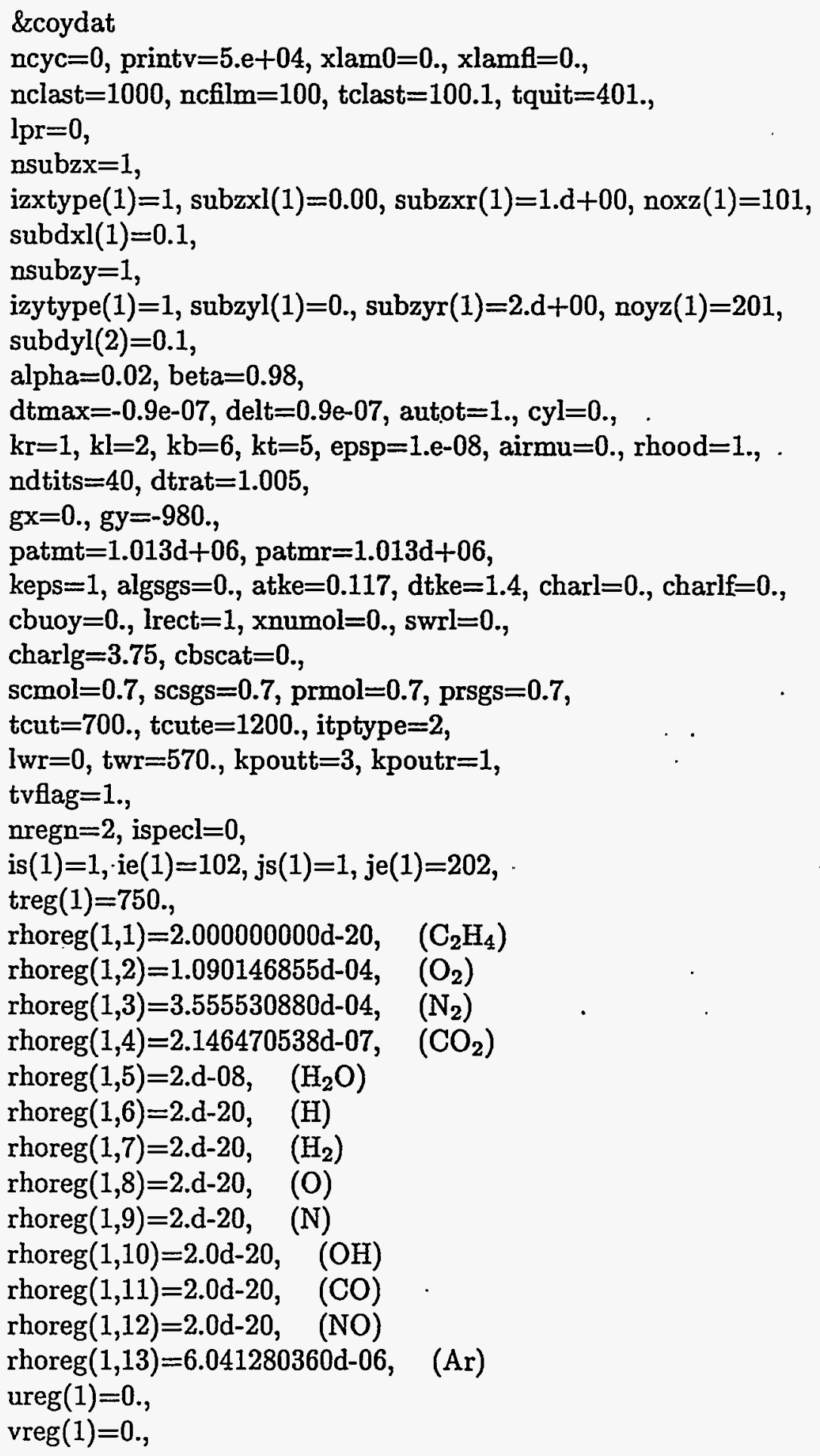




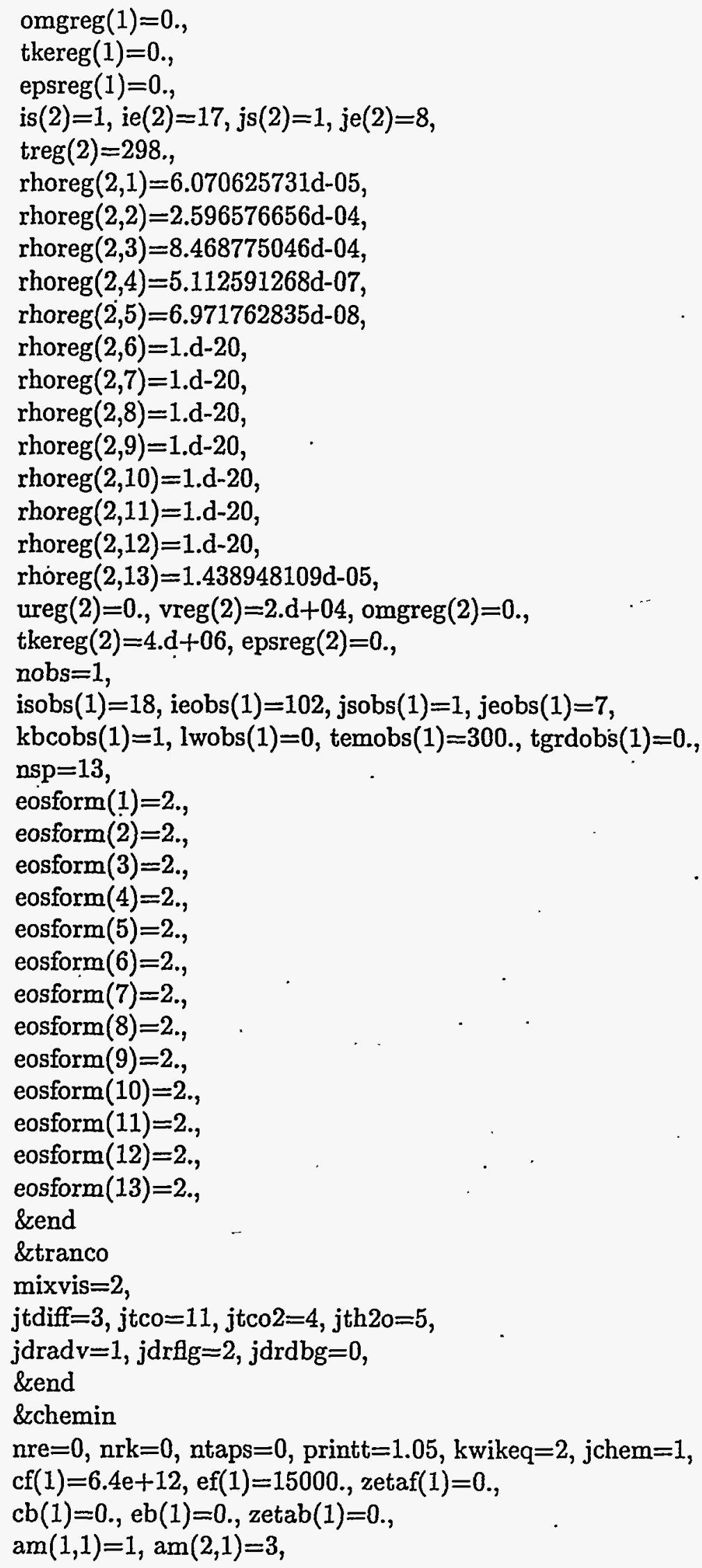




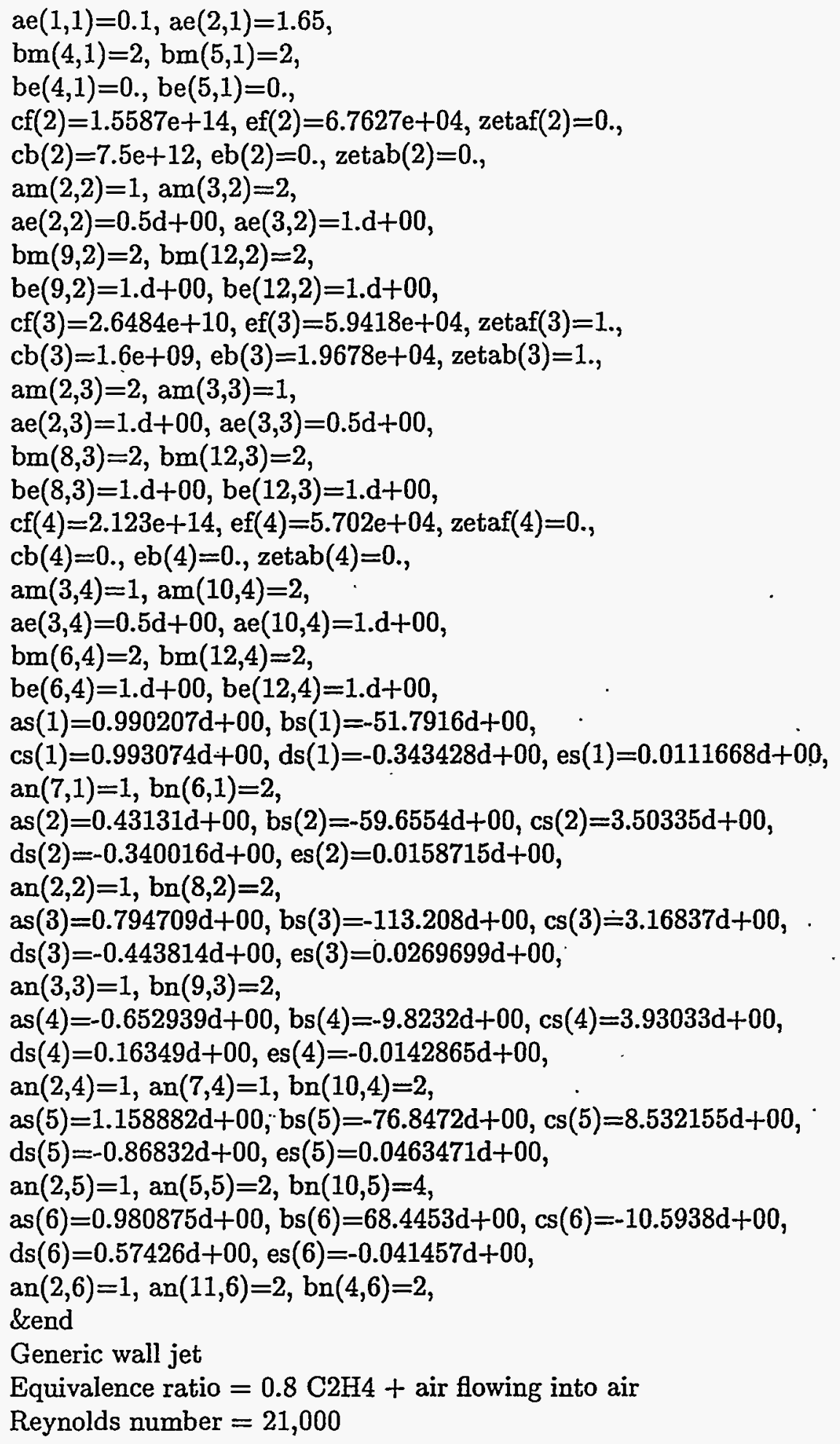




\section{Experimental Setup for In-cylinder Imaging of

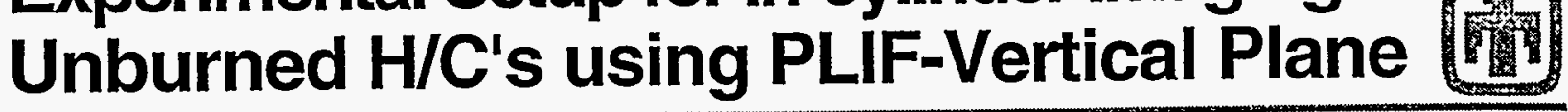

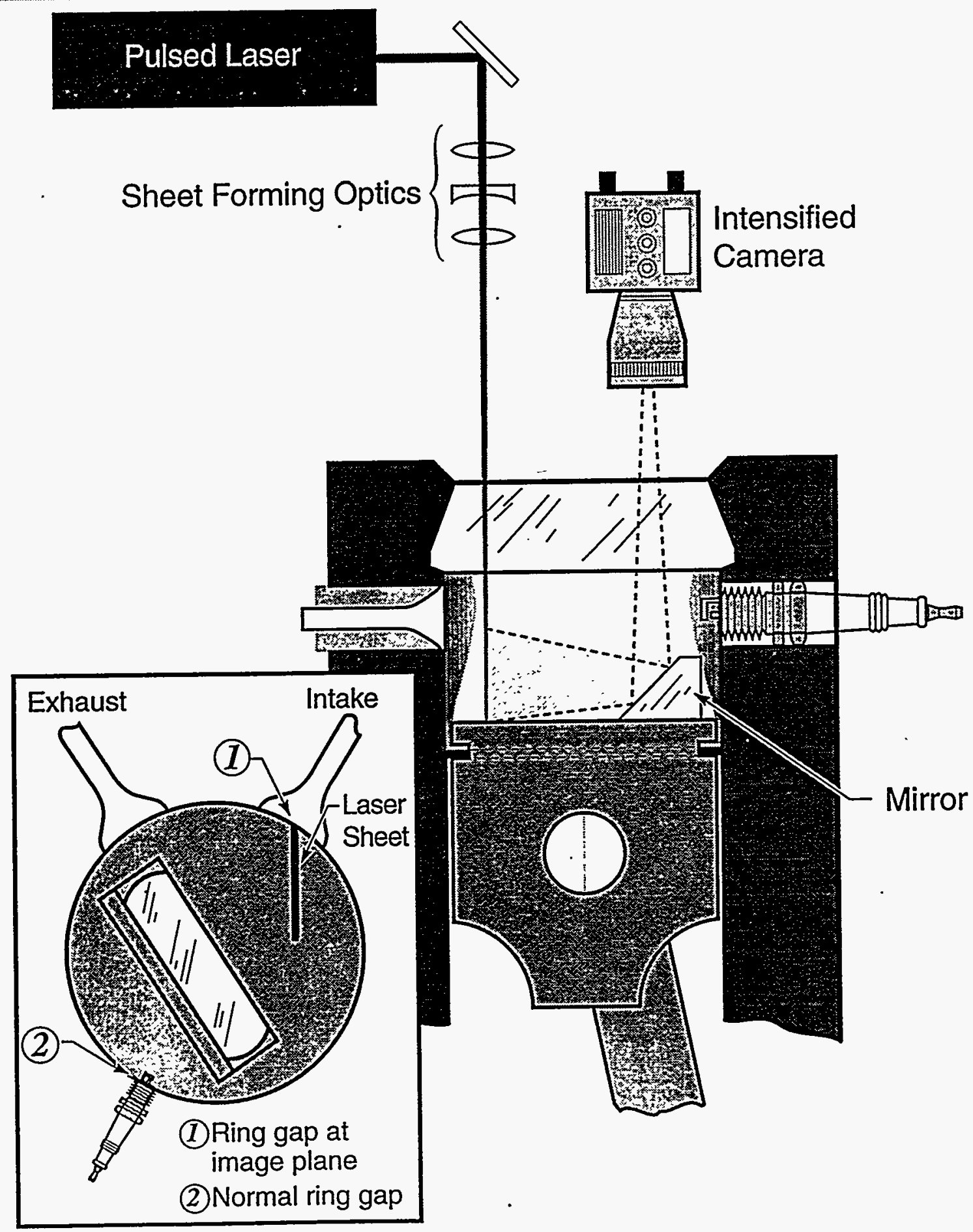

Fig. 1. Schematic of the PLIF apparatus used to make the images in Fig. 2. 


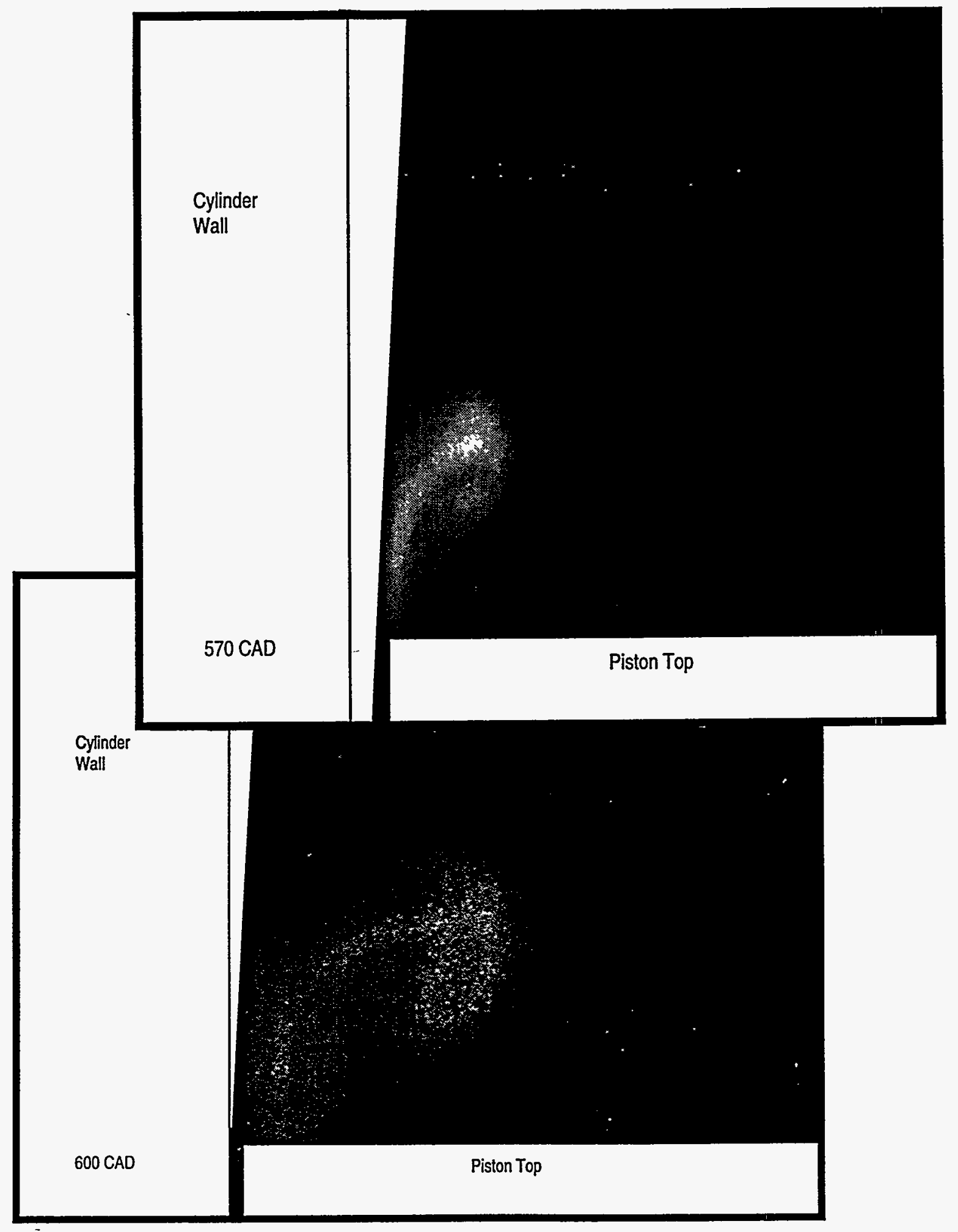

Fig. 2. PLIF images of acetone jetting from the top land crevice 57 (top panel) and 60 degrees (bottom panel) after bottom dead center. Since the laser sheet is not perpendicular to the cylinder wall, the images are stretched slightly in the horizontal direction. 

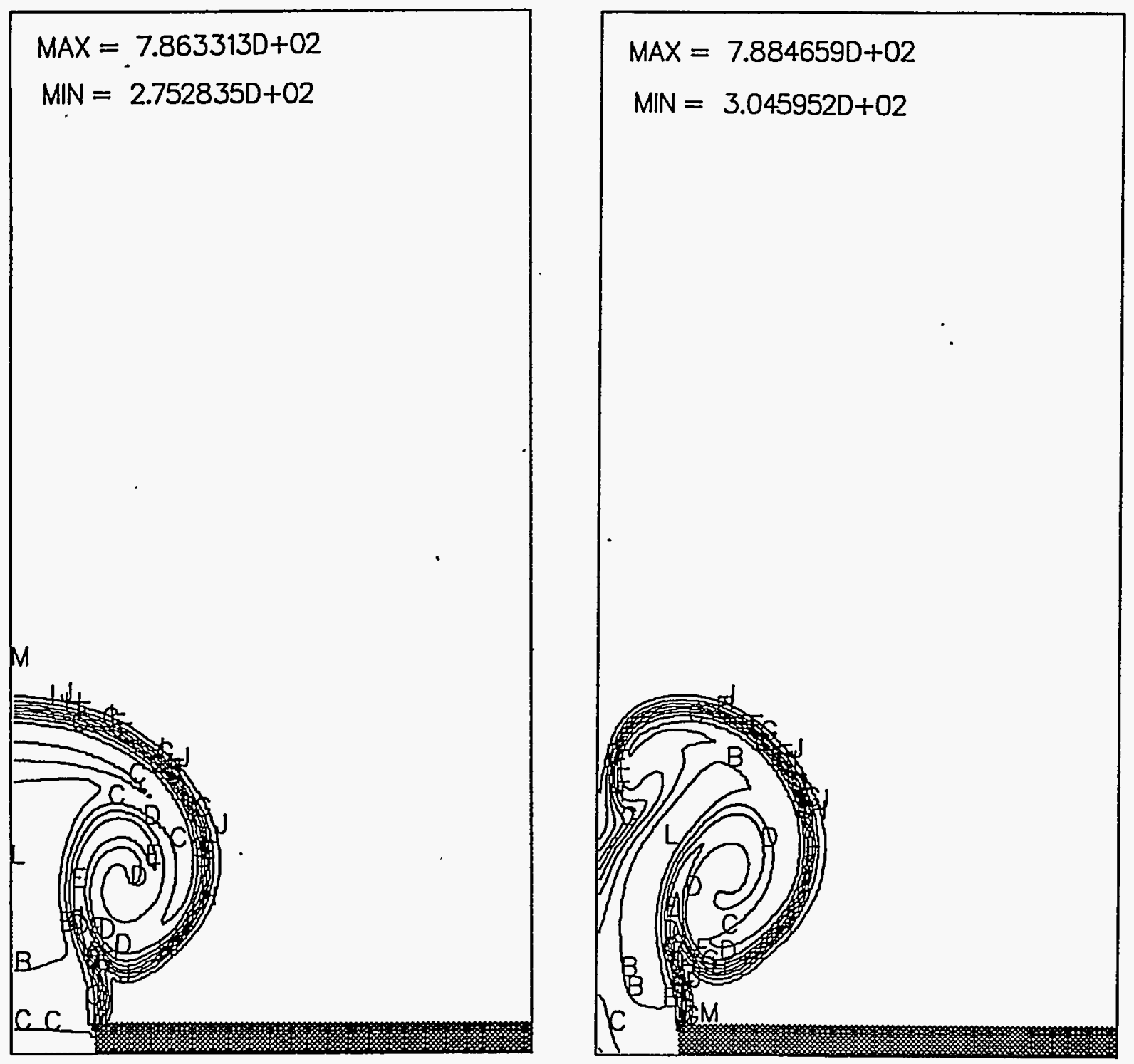

Fig. 3. Isotherms for the wall jet calculations slightly after $0.04 \mathrm{~ms}$. Cartesian geometry is assumed. The left and right boundaries of the two-dimensional grid are rigid walls, the solid bottom has an orifice for the jet, and the top is a fixed-pressure outflow boundary. The left panel has an adiabatic free-slip boundary condition, and the right panel has an adiabatic no-slip condition. 



Fig. 4. Mass fraction plots of ethylene for the same cases as in Fig. 3. 
$\operatorname{VMAX}=3.05980+04$

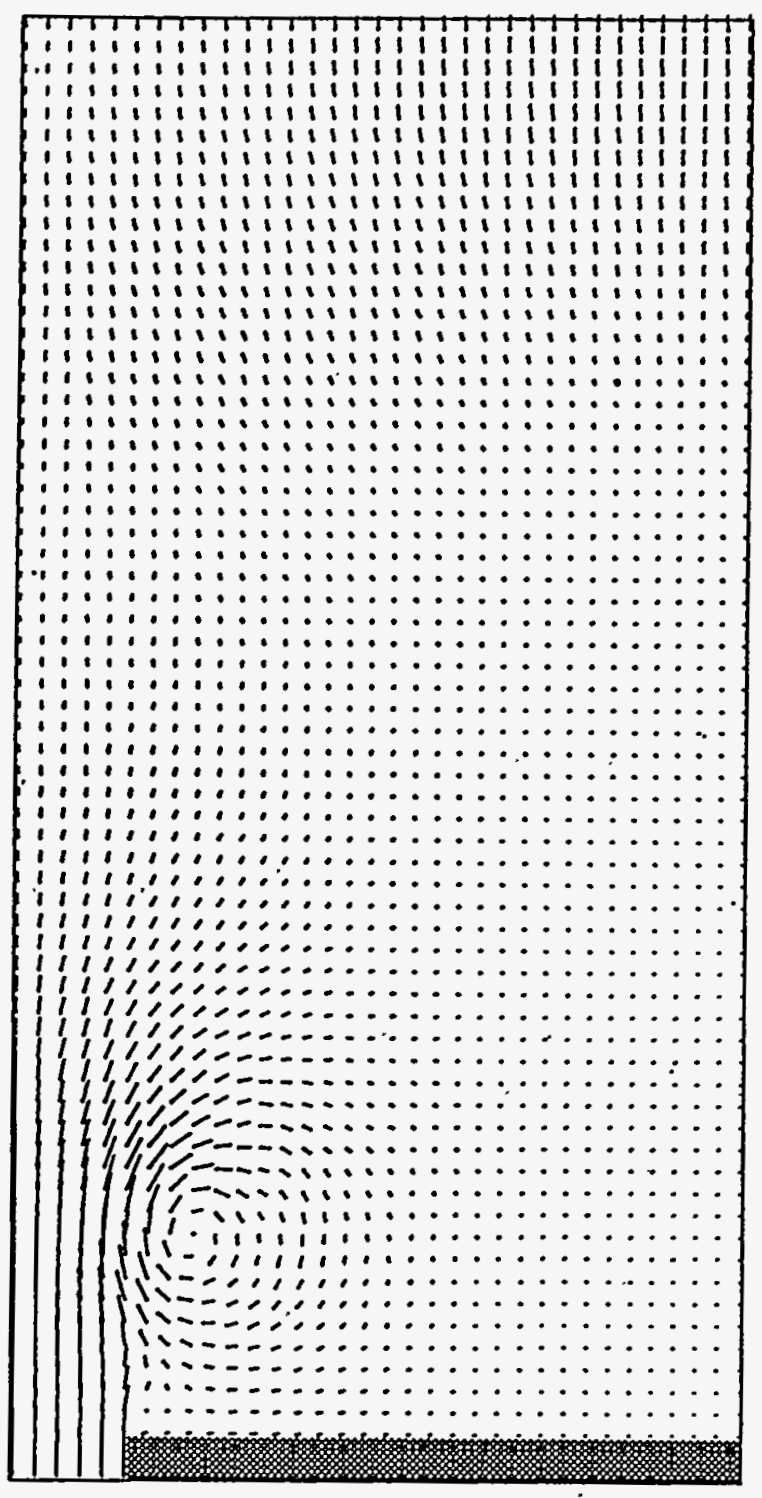

VMAX $=3.0945 D+04$

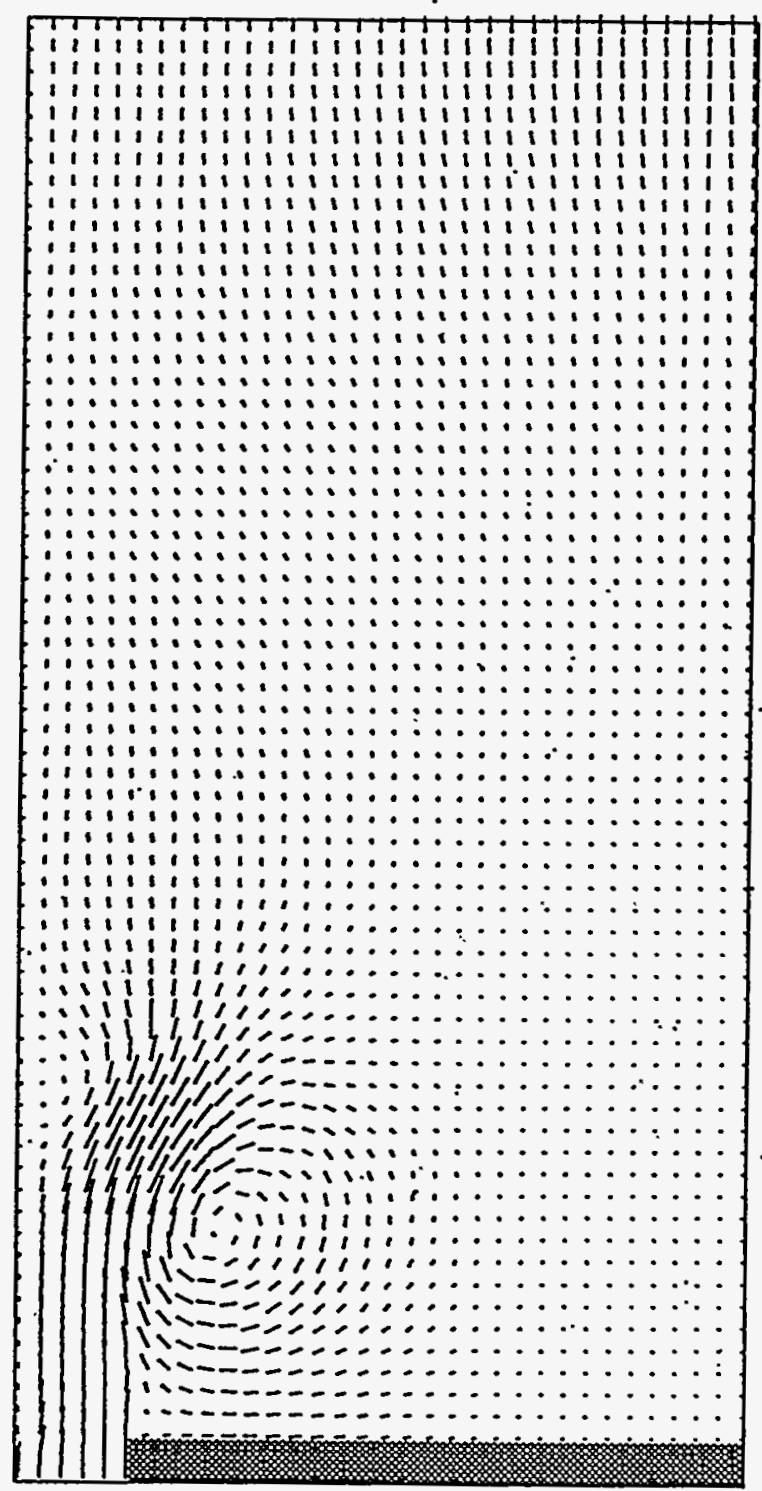

Fig. 5. Velocity vector plots for the same cases as in Fig. 3. Vectors are shown for every third zone. 
$\operatorname{VMAX}=3.13500+04$



Fig. 6. Velocity vector plot zoomed in to show the secondary vortex and reverse flow on the left wall. A vector is plotted for every zone. 

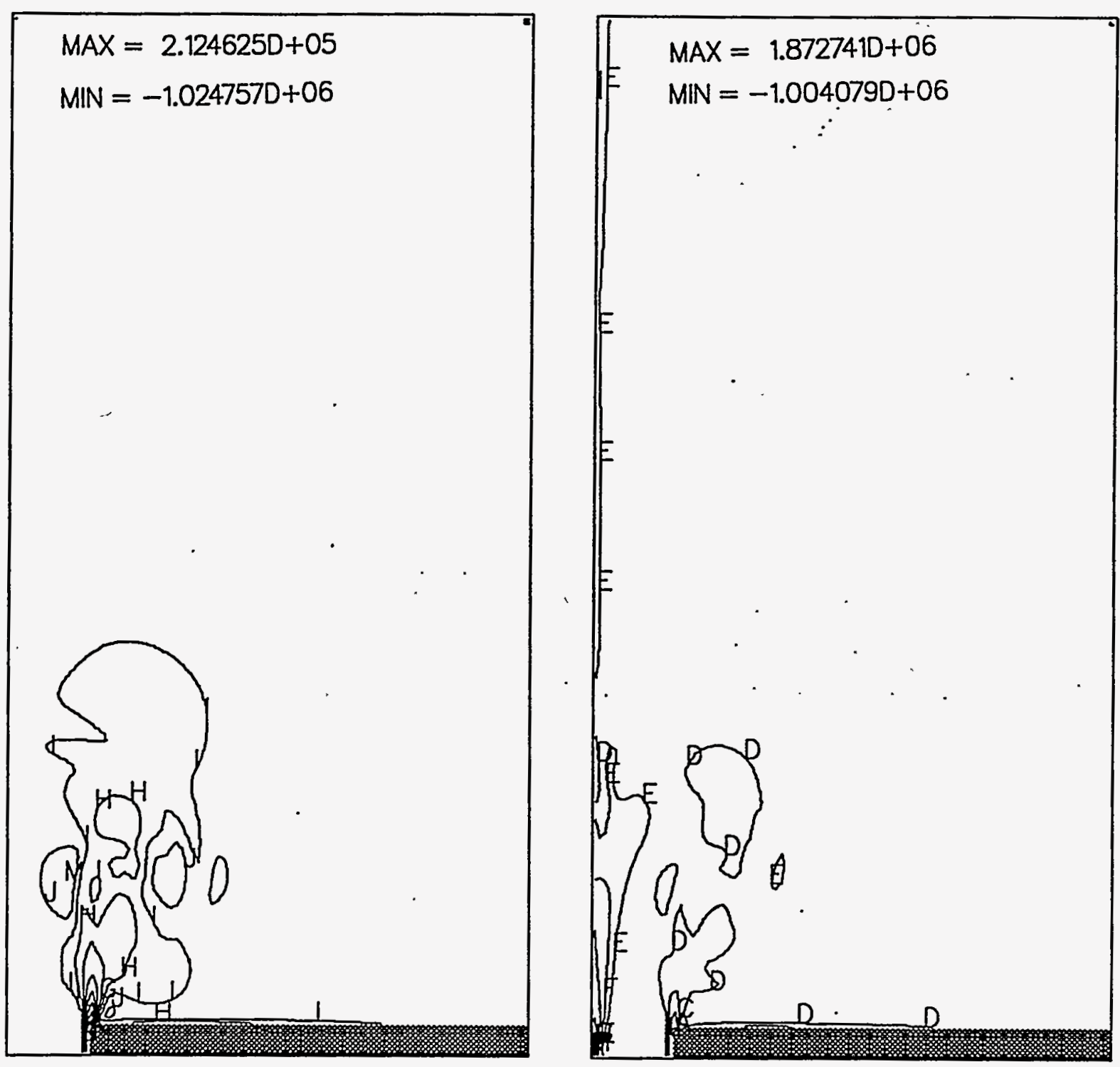

Fig. 7. Vorticity plots for the same cases as in Fig. 3. 



Fig. 8. Isotherms slightly after $0.1 \mathrm{~ms}$. 



Fig. 9. Mass fraction of ethylene for the same cases as in Fig. 7. 
VMAX $=2.82990+04$



VMAX $=2.9215 D+04$

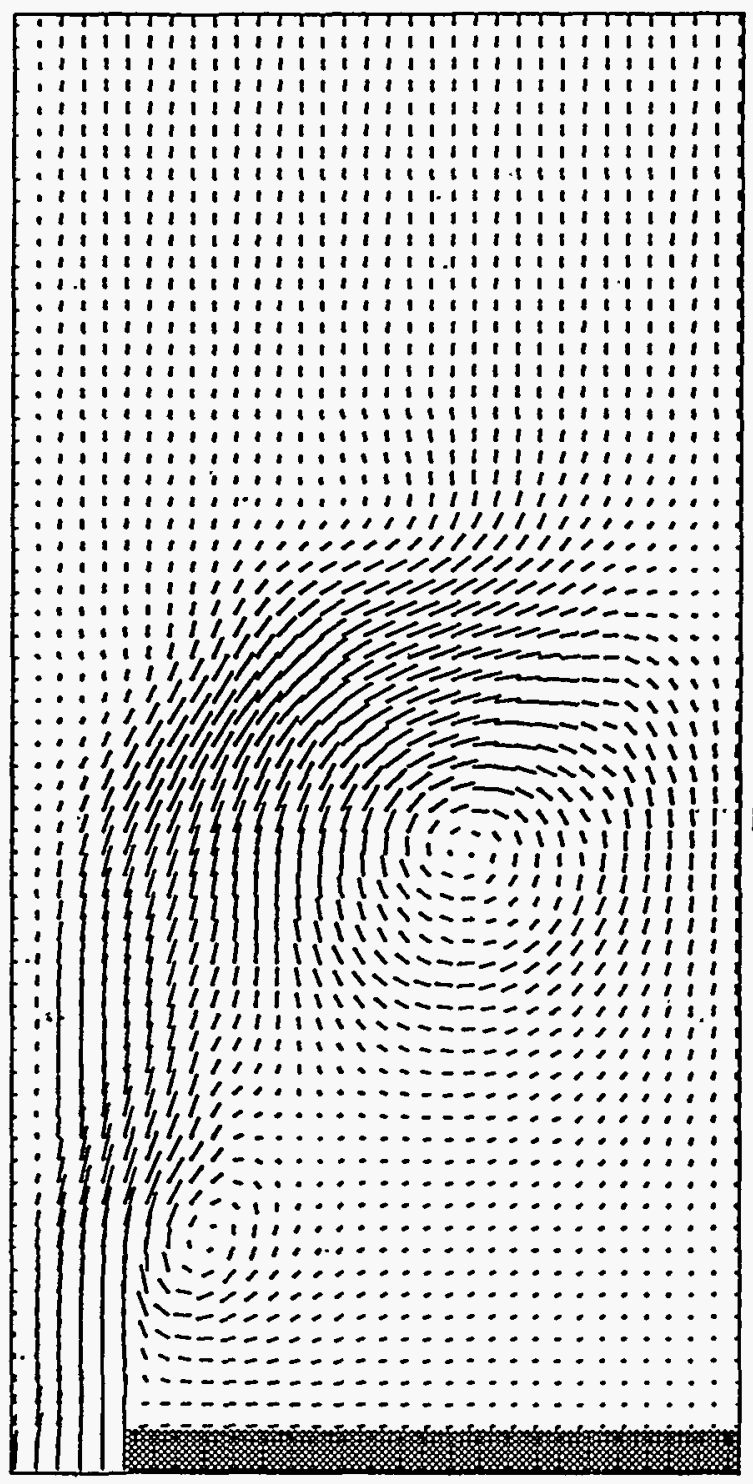

Fig. 10. Velocity vector plots for the same cases as in Fig. 7. 

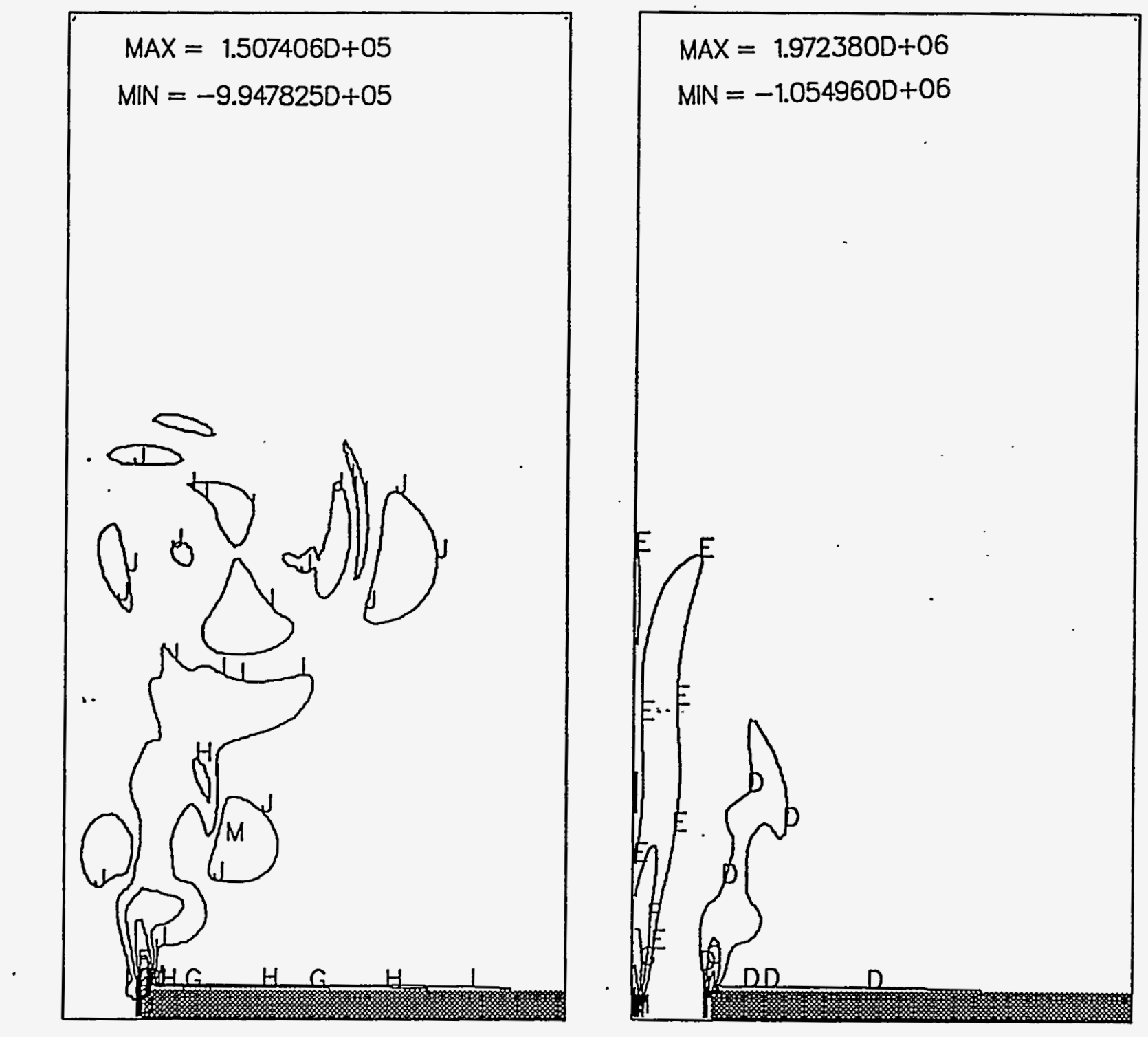

Fig. 11. Vorticity for the same cases as in Fig. 7. 

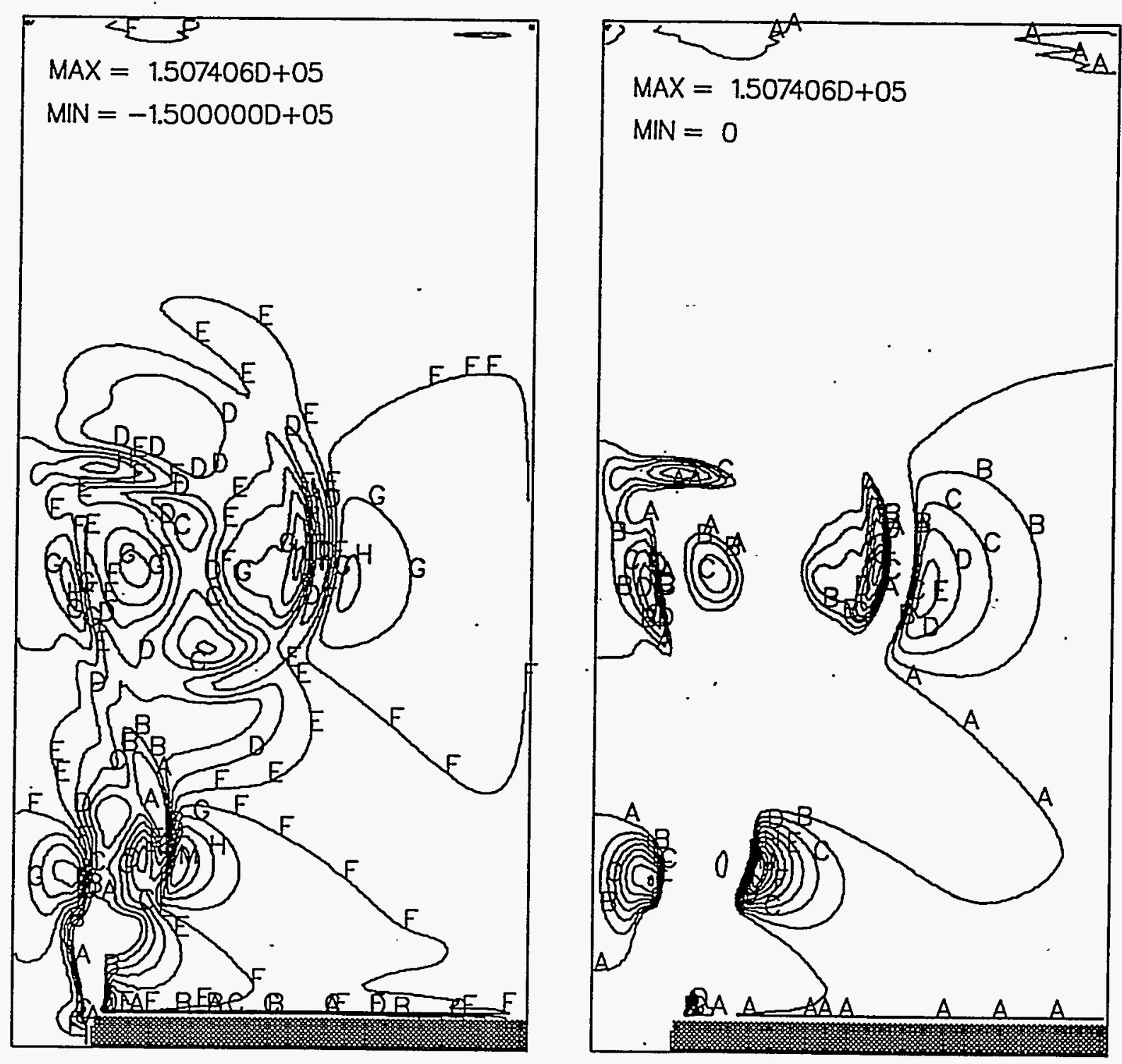

Fig. 12. Vorticity for the free-slip case in Fig. 10, but with contour values modified to highlight the tip vortices. The right panel shows only contours of positive vorticity. 

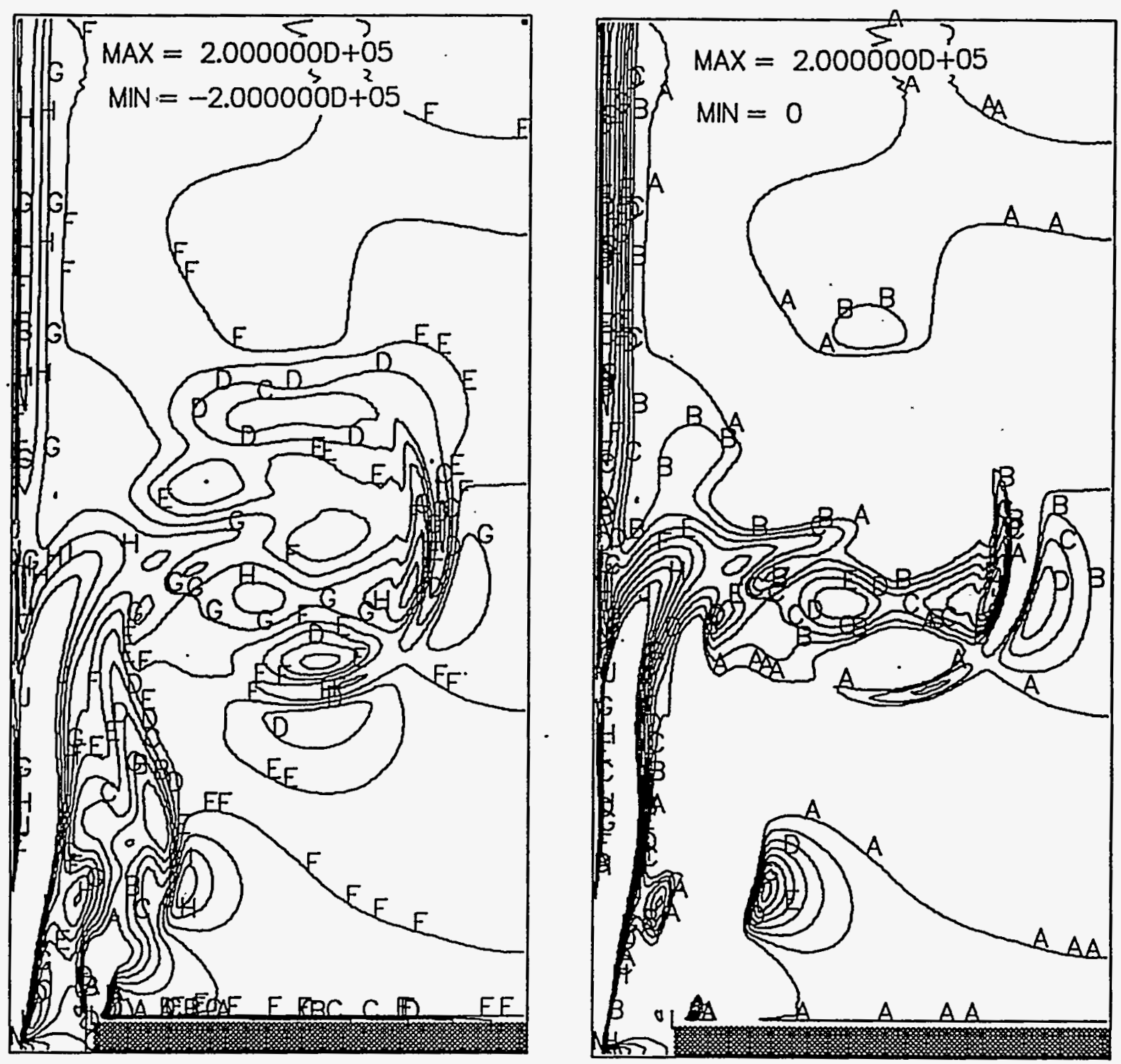

Fig. 13. Vorticity for the no-slip case in Fig. 10, but with contour values modified to highlight the tip vortices. The right panel shows only contours of positive vorticity. 



Fig. 14. Mass fraction of ethylene just before $0.14 \mathrm{~ms}$. 
$\operatorname{VMAX}=3.1683 \mathrm{D}+04$

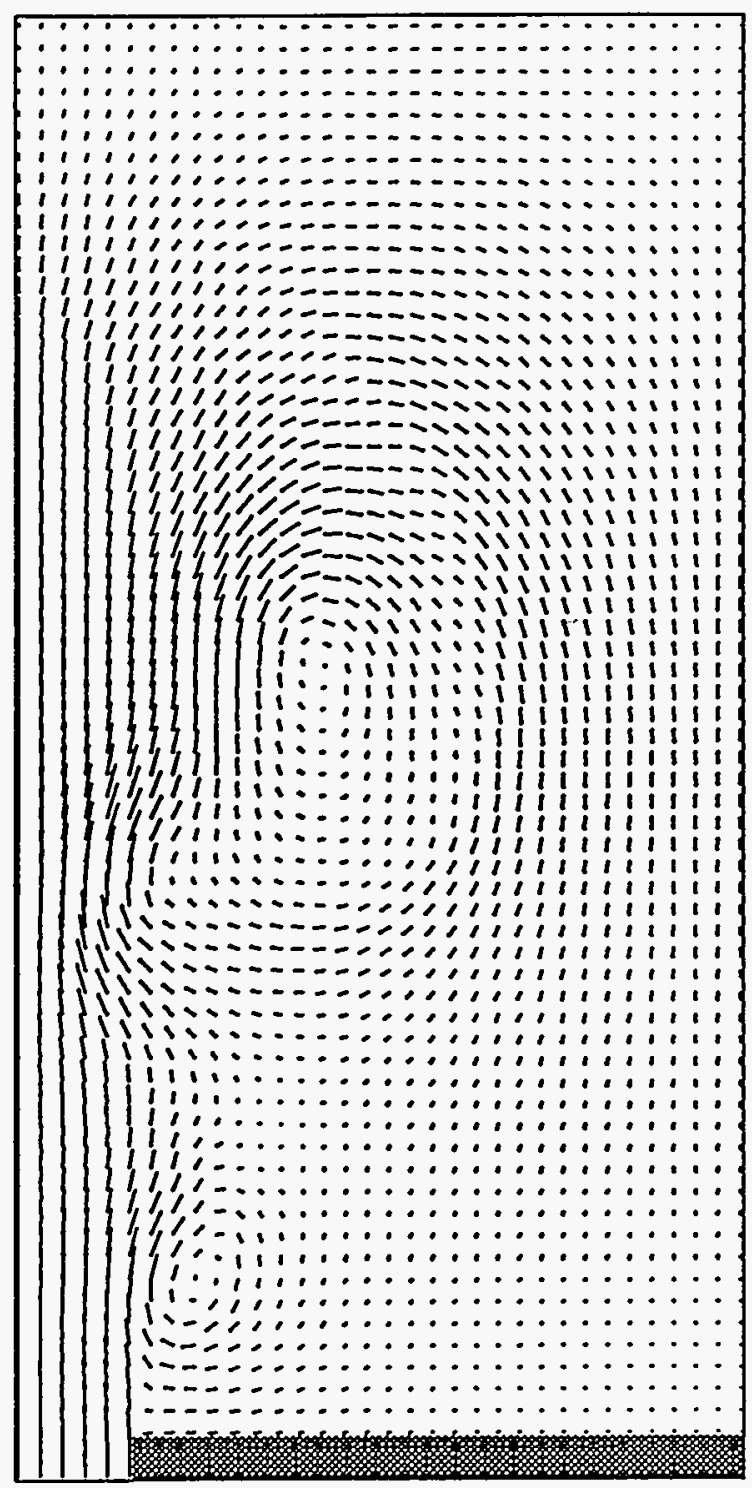

$\operatorname{VMAX}=3.3053 \mathrm{D}+04$



Fig. 15. Velocity vector plots for the same cases as in Fig. 10. 




Fig. 16. Fuel mass fraction plot for the no-slip solution with Reynolds number 210 at $11.7 \mathrm{~ms}$. 